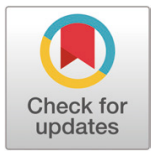

Received: Jul 27, 2020

Revised: Aug 6, 2020

Accepted: Aug 7, 2020

\#These authors contributed equally to this work.

*Corresponding author Mi-Kyung Park

School of Food Science and Biotechnology, and Food and Bio-Industry Research Institute, Kyungpook National University,

Daegu 41566, Korea.

Tel: +82-53-950-5776

E-mail: parkmik@knu.ac.kr

Copyright $(\subset 2020$ Korean Society of Animal Sciences and Technology. This is an Open Access article distributed under the terms of the Creative Commons Attribution Non-Commercial License (http:// creativecommons.org/licenses/by$\mathrm{nc} / 4.0 /$ ) which permits unrestricted non-commercial use, distribution, and reproduction in any medium, provided the original work is properly cited.

ORCID

In Young Choi

https://orcid.org/0000-0003-3730-5193 Do Hyeon Park

https://orcid.org/0000-0002-9419-6563

Cheonghoon Lee

https://orcid.org/0000-0002-6382-5611

Jinyoung Lee

https://orcid org/0000-0002-2908-8240

Mi-Kyung Park

https://orcid.org/0000-0003-1182-6046

\section{Exploring the feasibility of Salmonella Typhimurium-specific phage as a novel bio-receptor}

\author{
In Young Choi ${ }^{1 \#}$, Do Hyeon Park" ${ }^{1 \#}$, Brayan A. Chin ${ }^{2}$, Cheonghoon Lee ${ }^{3}$, \\ Jinyoung Lee ${ }^{4}$ and Mi-Kyung Park ${ }^{1 *}$
}
${ }^{1}$ School of Food Science and Biotechnology, and Food and Bio-Industry Research Institute, Kyungpook National University, Daegu 41566, Korea
${ }^{2}$ Materials Research and Education Center, Auburn University, Auburn, AL 36849, USA
${ }^{3}$ Graduate School of Public Health, and Institute of Health and Environment, Seoul National University, Seoul 08826, Korea
${ }^{4}$ Gyedong General Education Institute, Sangmyung University, Cheonan 31066, Korea

\section{Abstract}

The purpose of this study was aimed to isolate a Salmonella Typhimurium-specific phage (KFS-ST) from washing water in a poultry processing facility and to investigate the feasibility of the KFS-ST as a novel bio-receptor for the magnetoelastic (ME) biosensor method. KFSST against $\mathrm{S}$. Typhimurium was isolated, propagated, and purified using a $\mathrm{CsCl-gradient} \mathrm{ul-}$ tracentrifugation. Morphological characteristics of KFS-ST were analyzed using transmission electron microscopy (TEM). Its specificity and efficiency of plating analysis were conducted against 39 foodborne pathogens. The temperature and pH stabilities of KFS-ST were investigated by the exposure of the phage to various temperatures $\left(-70^{\circ} \mathrm{C}-70^{\circ} \mathrm{C}\right)$ and $\mathrm{pHs}(1-12)$ for $1 \mathrm{~h}$. A one-step growth curve analysis was performed to determine the eclipse time, latent time and burst size of phage. The storage stability of KFS-ST was studied by exposing KFSST to various storage temperatures $\left(-70^{\circ} \mathrm{C},-20^{\circ} \mathrm{C}, 4^{\circ} \mathrm{C}\right.$, and $\left.22^{\circ} \mathrm{C}\right)$ for 12 weeks. KFS-ST was isolated and purified with a high concentration of $(11.47 \pm 0.25) \mathrm{Log} P F U / \mathrm{mL}$. It had an icosahedral head $(56.91 \pm 2.90 \mathrm{~nm})$ and a non-contractile tail $(225.49 \pm 2.67 \mathrm{~nm})$, which was classified into the family of Siphoviridae in the order of Caudovirales. KFS-ST exhibited an excellent specificity against only $S$. Typhimurium and $S$. Enteritidis, which are considered two of the most problematic Salmonella strains in the meat and poultry. However, KFS-ST did not exhibit any specificity against six other Salmonella and 27 non-Salmonella strains. KFS-ST was stable at temperature of $4{ }^{\circ} \mathrm{C}$ to $50^{\circ} \mathrm{C}$ and at $\mathrm{pH}$ of 4 to 12 . The eclipse time, latent time, and burst size of KFS-ST were determined to be $10 \mathrm{~min}, 25 \mathrm{~min}$ and $26 \mathrm{PFU} /$ infected cell, respectively. KFS-ST was relatively stable during the 12-week storage period at all tested temperatures. Therefore, this study demonstrated the feasibility of KFS-ST as a novel bio-receptor for the detection of $S$. Typhimurium and $S$. Enteritidis in meat and poultry products using the ME biosensor method.

Keywords: Salmonella-specific phage, Bio-receptor, Magnetoelastic biosensor, Meat and poultry 
Competing interests No potential conflict of interest relevant to this article was reported.

Funding sources

This research was supported by Kyungpook National University Bokhyeon Research Fund, 2017.

Acknowledgements Not applicable.

Availability of data and material Upon reasonable request, the datasets of this study can be available from the corresponding author.

Authors' contributions Conceptualization: Park MK. Data curation: Park DH, Lee C Formal analysis: Choi IY. Methodology: Choi IY, Park DH Investigation: Lee J, Park MK. Writing - original draft: Choi IY, Park DH Writing - review \& editing: Choi IY, Chin BA

Ethics approval and consent to participate This article does not require IRB/IACUC approval because there are no human and animal participants.

\section{INTRODUCTION}

Salmonella is the most prevalent foodborne pathogen and there are approximately 1.4 million Salmonella infections (salmonellosis), 26,500 hospitalizations, and 420 deaths in the United States every year [1]. Salmonella consists of 2,600 serotypes that are divided into two species including $S$. enterica and S. bongori. Among these, approximately $99 \%$ of Salmonella serotypes cause salmonellosis in humans or other mammals [2]. The general symptoms of salmonellosis are characterized as fever, headache, abdominal pain, diarrhea or constipation, vomiting and nausea [3]. The incubation period for salmonellosis is approximately 12 to $72 \mathrm{~h}$, and the infections dosage is reported to be in the range of $10^{3}$ to $10^{6}$ organisms depending on the host, Salmonella strain, and food matrix [4]. Approximately 95\% of salmonellosis is caused by the consumption of Salmonella-contaminated food products [1,5]. Its outbreaks have been associated with meat, poultry, eggs, milk, and dairy products as well as fresh produce [3]. Notably, $S$. Typhimurium and $S$. Enteritidis have been ranked the most frequent Salmonella serotypes in the world (26.1\% in USA, 68.3\% in Europe, and 64.8\% in Korea) [6,7].

In Korea, pork, poultry, and beef are the second largest consumed food group after grains [5]. The consumption of meat and poultry products has steadily increased almost three fold in 2014 when compared to 1985 [5]. This increase of meat and poultry consumption has provided a greater risk of Salmonella exposures to consumers. Since Salmonella existed in the intestinal tracts of meat and poultry, the highest prevalence of Salmonella is in chicken (18.8\%-30.3\%), followed by pork (5\%-21\%), and then beef (1.2\%-2.0\%) [5]. Thus, the Korean government has implemented the HACCP (Hazard Analysis and Critical Control Point) for the pork industry in 2006, beef industry in 2007 and poultry industry in 2008 for the control of Salmonella [5,8]. Therefore, more rapid, sensitive, specific, simple, and hand-held detection methods are required for on-site applicable Salmonella detection [9].

Due to the necessities of the on-site detection method for Salmonella, a phage-based magnetoelastic (ME) biosensor has been developed as a novel, wireless, and direct detection method for onsite use $[10,11]$. The phage-based ME biosensor is composed of an ME sensor made from a magnetostrictive material that elongates or contracts (vibration) under an applied magnetic field. This vibration will provide the unique resonant frequency value for each $\mathrm{ME}$ sensor, which is measured by a network analyzer. Once the ME sensor is immobilized with a specific phage depending on the target pathogen, the phage-immobilized sensor is placed directly on the surface of food. As long as the specific phage binds with the target pathogen on the food, the mass of the ME sensor will increase so that the vibration of $\mathrm{ME}$ sensor decreases due to its heaviness. This reduced vibration changes the original resonant frequency of the sensor so that the resonant frequency shift represents the quantified and qualified numbers of target pathogens bound on the ME sensor. ME biosensors have been successfully implemented to detect $S$. Typhimurium on fresh produce such as spinaches [11], tomatoes [11], and cantaloupes [10]. In their studies, the E2 phage was employed on the ME biosensor method after the E2 phage was genetically modified from a filamentous fd phage. Further studies also reported that the E2 phage-based ME biosensor method was employed to detect $S$. Typhimurium in milk [12] and egg shells [13]. Another study [14] reported the use of the C422 phage, which was genetically modified from filamentous fd phage, for all Salmonella enterica serovars detection on chicken breast. However, most phage-based ME biosensor methods have been focused on the detection of Salmonella on fresh produce rather than meat and poultry products by using genetically modified filamentous type phages.

For the successful application of ME sensor to poultry products, the selection of an appropriate and optimum bio-receptor is necessary to interact with a specific target pathogen that exist in poul- 
try. Phage (bacteriophage) has been gaining more attentions over several bio-receptors including antibodies, cell, enzyme, and DNA. Phages possess excellent specificity, robustness under harsh conditions ( $\mathrm{pH}$, temperature), safety, and relatively cheap and easy production processes [9]. Phages, as a natural predator of bacteria, are viruses that infect the bacteria cell specifically. They consist of DNA or RNA enclosed within a protein coat and can undergo either lytic or lysogenic cycles due to its simple structure. During the lytic cycle, a phage attaches to the host bacteria, replicates, and finally lyses the host bacteria to release the phages. Although a lysogenic phage can also integrate with the host bacteria by introducing phage DNA into the bacterial DNA, the prophage exists in the host bacteria without any replication or lysis of phages from the host bacteria. Among these unique properties, the lytic property and specificity of phage can confer an added advantage for the isolation of a specific phage from co-existing and numerous hosts and phages. In addition, the successful investigation of a phage against its target will guarantee the specificity, reliability, and applicability of the ME biosensor method. Due to these advantages of lytic phages, $S$. Typhimurium-specific phage was isolated and purified from a poultry processing facility and the feasibility of $S$. Typhimurium-specific phage as a bio-receptor was then investigated for its employment to ME biosensor method.

\section{MATERIALS AND METHODS}

\section{Bacterial strains and growth conditions}

Indicator (S. Typhimurium ATCC 13311) and other bacterial strains used in the specificity study were obtained from the American Type of Culture Collection (ATCC), National Culture Collection for Pathogens (NCCP) and a laboratory in the Department of Plant and Food Sciences (DPFS) at Sangmyung University in Chungnam, Korea. Each bacterial strain was cultivated in $25 \mathrm{~mL}$ of tryptic soy broth (TSB, Difco Laboratories, Sparks, MD, USA) for $16 \mathrm{~h}$ at $37^{\circ} \mathrm{C}$ with shaking at $110 \mathrm{rpm}$. After being washed three times with sterilized phosphate-buffered saline (PBS, $\mathrm{pH}$ 7.4, Life Technologies, Paisley, UK) buffer by centrifugation at 7,000×g for $4 \mathrm{~min}$, the bacterial cell was suspended in PBS. The concentration of the indicator strain and each bacterial suspension was adjusted to $10^{8} \mathrm{CFU} / \mathrm{mL}$ using pre-constructed standard curves.

\section{Isolation and purification of phages}

An aliquot of $25 \mathrm{~mL}$ of washing water obtained from a poultry processing facility (Orpum, Sangju, Korea) was mixed with $225 \mathrm{~mL}$ of TSB containing $1 \mathrm{~mL}$ of the indicator strain suspension. After incubation for $16 \mathrm{~h}$ at $37^{\circ} \mathrm{C}$ with gentle shaking at $160 \mathrm{rpm}$, the mixtures were centrifuged at 4,000×g for $10 \mathrm{~min}$ at $4^{\circ} \mathrm{C}$, followed by filtration of the supernatant using a $0.20-\mu \mathrm{m}$ cellulose acetate filter (Advantec Toyo Kaisha, Tokyo, Japan). An aliquot of $10 \mu \mathrm{L}$ of the filtrate was dotted on the surface of pre-solidified TA soft agar ( $4 \mathrm{~g}$ agar, $8 \mathrm{~g}$ nutrient broth, $5 \mathrm{~g} \mathrm{NaCl}, 0.2 \mathrm{~g} \mathrm{MgSO}$, $0.05 \mathrm{~g} \mathrm{MnSO}_{4}$, and $0.15 \mathrm{~g} \mathrm{CaCl}_{2}$ per $1 \mathrm{~L}$ ) containing $200 \mu \mathrm{L}$ of the indicator strain suspension. The presence of phages in the filtrate was then confirmed using a dot assay [9]. Once the formation of a clear zone was observed, a plaque assay was performed to isolate single phages from the filtrate. An aliquot of $100 \mu \mathrm{L}$ of the serially diluted filtrate and $200 \mu \mathrm{L}$ of the indicator strain suspension were inoculated into $4 \mathrm{~mL}$ of TA soft agar and then, poured onto a tryptic soy agar (TSA, Difco Laboratories, Sparks, MD, USA) plate. After incubation for $16 \mathrm{~h}$ at $37^{\circ} \mathrm{C}$, each plaque was picked with a customized tip and eluted with sodium chloride-magnesium sulphate (SM) buffer $(50 \mathrm{mM}$ Tris- $\mathrm{HCl}, 100 \mathrm{mM} \mathrm{NaCl}, 10 \mathrm{mM} \mathrm{MgSO}_{4}, \mathrm{pH} 7.5$ ) with vigorous agitation for $1 \mathrm{~h}$ at $22^{\circ} \mathrm{C}$. All of these procedures were repeated until the single phage was isolated [9]. To increase of the concentration of the single phage, $3 \mathrm{~mL}$ of TA broth containing $1 \%(\mathrm{v} / \mathrm{v})$ indicator strain suspension was 
incubated for $2.5 \mathrm{~h}$ at $37^{\circ} \mathrm{C}$. The eluted single phage was then added to the TA broth mixture and incubated for $2.5 \mathrm{~h}$ at $37^{\circ} \mathrm{C}$ After centrifugation at $2,400 \times \mathrm{g}$ for $10 \mathrm{~min}$ at $4{ }^{\circ} \mathrm{C}$, the supernatant was filtered through a $0.20-\mu \mathrm{m}$ cellulose acetate filter. The dot assay was performed to determine the phage concentration. All of these procedures were repeated by increasing the volume of TA broth and indicator strain suspension until phage concentration reached up to $10^{10}$ plaque forming unit $(\mathrm{PFU}) / \mathrm{mL}$. The propagated filtrate was mixed with $10 \%(\mathrm{w} / \mathrm{v})$ of polyethylene glycol 6000 (Sigma-Aldrich, St. Louis, MO, USA) and $10 \mathrm{~mL}$ of $1 \mathrm{M} \mathrm{NaCl}$, followed by precipitation at $4{ }^{\circ} \mathrm{C}$ for $16 \mathrm{~h}$. After centrifugation at 7,200 $\times \mathrm{g}$ for $20 \mathrm{~min}$ at $4^{\circ} \mathrm{C}$, the pellet was suspended in $\mathrm{SM}$ buffer and the suspension was purified by performing $\mathrm{Cs} C l$ gradient ultracentrifugation at $39,000 \times \mathrm{g}$ for $2 \mathrm{~h}$ at $4^{\circ} \mathrm{C}$. Finally, the layer of bluish opalescent phage band fraction was separated from the centrifuge tube and dialyzed. The final concentration of the purified phage (indicated as KFS-ST hereafter) was determined using plaque assay and stored at $4^{\circ} \mathrm{C}$ until further use.

\section{Morphological characteristics of KFS-ST}

Five microliters of KFS-ST $\left(10^{9} \mathrm{PFU} / \mathrm{mL}\right)$ were adsorbed on the top of a carbon-coated copper grid and negatively stained with 4\% phosphotungstic acid (Sigma-Aldrich, St. Louis, MO, USA). The KFS-ST was observed using a TEM (H-7100, Hitachi, Tokyo, Japan) at an accelerating voltage of $100 \mathrm{kV}$ with 50,000 to $200,000 \times$ magnifications.

\section{Specificity and efficiency of plating analysis (EOP) of KFS-ST}

Dot assay was performed to identify the specificity of KFS-ST against various bacterial strains. Once a clear zone was formed, a plaque assay was performed and EOP value was calculated by dividing the number of plaques on each bacterial strain by the number of plaques on the host bacteria.

\section{Temperature and pH stabilities of KFS-ST}

The temperature and $\mathrm{pH}$ stabilities of KFS-ST were investigated by exposing KFS-ST $\left(10^{6} \mathrm{PFU} /\right.$ $\mathrm{mL}$ ) at various temperatures $\left(-70^{\circ} \mathrm{C},-20^{\circ} \mathrm{C}, 4^{\circ} \mathrm{C}, 10^{\circ} \mathrm{C}, 20^{\circ} \mathrm{C}, 30^{\circ} \mathrm{C}, 40^{\circ} \mathrm{C}, 50^{\circ} \mathrm{C}, 60^{\circ} \mathrm{C}\right.$, and $\left.70^{\circ} \mathrm{C}\right)$ and $\mathrm{pHs}(1,2,3,4,5,6,7,8,9,10,11$, and 12) using a plaque assay. An aliquot of $100 \mu \mathrm{L}$ of KFSST was added into $900 \mu \mathrm{L}$ of TSB and incubated at various temperatures for $1 \mathrm{~h}$ and various $\mathrm{pHs}$ at $22^{\circ} \mathrm{C}$ for $1 \mathrm{~h}$, respectively.

\section{One-step growth curve of KFS-ST}

One percent of the host suspension was sub-inoculated into fresh TSB medium and incubated until 1.0 of $\mathrm{OD}_{640}$. KFS-ST was added at the multiplicity of infection of 0.01 and incubated for 25 min at $37^{\circ} \mathrm{C}$ to allow absorption of KFS-ST to the surface of the host cell, which was determined by the previous study. After adsorption, the mixture was centrifuged at $11,400 \times \mathrm{g}$ for $10 \mathrm{~min}$ at $4^{\circ} \mathrm{C}$ to remove the unabsorbed KFS-ST. The pellet was then resuspended with TSB and incubated at $37^{\circ} \mathrm{C}$. At every 5 -min interval, $1 \mathrm{~mL}$ of the incubated mixture was collected and evenly divided into two portions to add $1 \%(\mathrm{v} / \mathrm{v})$ of chloroform for the release of intracellular KFS-ST. After $30 \mathrm{~s}$, a plaque assay was performed to determine the eclipse time, latent time, and burst size of KFS-ST.

\section{Storage stability of KFS-ST}

KFS-ST $\left(10^{9} \mathrm{PFU} / \mathrm{mL}\right)$ in TA broth was stored at $-70^{\circ} \mathrm{C},-20^{\circ} \mathrm{C}, 4^{\circ} \mathrm{C}$, and $22^{\circ} \mathrm{C}$ to investigate the storage stability of phage. In order to prevent any damage in the freezing process, $15 \%(\mathrm{v} / \mathrm{v})$ glycerol was added into TA broth and stored at $-70^{\circ} \mathrm{C}$ and $-20^{\circ} \mathrm{C}$, respectively. At every 2-week interval, each sample was collected and plaque assay was performed to measure the stability of KFS-ST during the 12 weeks under various storage temperatures. 


\section{Statistical analysis}

The experiment was replicated at least three times and the experimental results were expressed as mean \pm SD. All statistical analyses were performed with GraphPad and InStatV.3 programs (GraphPad, San Diego, CA, USA). The student's paired $t$-test for two groups and the one-way analysis of variance (ANOVA) among more than two groups were used for the comparison. The significance level was determined at $p<0.05$ or $p<0.001$.

\section{RESULTS AND DISCUSSION}

\section{Purification of KFS-ST and its morphological characteristic}

KFS-ST was isolated and purified from washing water used in a poultry processing facility with a concentration of $(11.47 \pm 0.25) \log \mathrm{PFU} / \mathrm{mL}$. The isolated and purified single phage was named KFS-ST following the recommendation of Ackermann's study [15], implying that the ST indicated the host genus and species name of Salmonella. For the morphological characterization of KFS-ST, a TEM image showed that KFS-ST has an icosahedral head and a non-contractile tail (Fig. 1). The width and length of the icosahedral head and tail were $59.90 \pm 3.07 \mathrm{~nm}$ and $56.91 \pm 2.90 \mathrm{~nm}$, and $13.77 \pm 1.78 \mathrm{~nm}$ and $225.49 \pm 2.67 \mathrm{~nm}$, respectively. In addition, it was confirmed that KFS-ST phage had a non-contractile tail because 20 TEM images showed that the tail length was almost the same (Fig. 1B). These results indicate that KFS-ST belongs to the family of Siphoviridae in the order of Caudovirales. To our knowledge, $31 \mathrm{~S}$. Typhimurium-specific phages belonging to the order of Caudovirales have been reported including 15 Siphoviridae, 9 Myoviridae and 7 Podoviridae (Table 1). Among these, 18 phages were isolated and purified from an animal itself or animal-related sewages such as cattle, swine and poultry. The head length of KFS-ST was similar to that of most reported phages of Siphoviridae, such as fmb-p1 [16], $\varphi$ STIz1 [17] and ES18 [18]. Interestingly, the tail length of our phage was the longest among others reported Siphoviridae phages, which was a very unique morphological characteristic. These data support the novelty of our KFS-ST in regards to the morphological aspect.

\section{Specificity and efficiency of plating analysis of KFS-ST}

The specificity of the bio-receptor in an analytical biosensor method is defined as the ability to
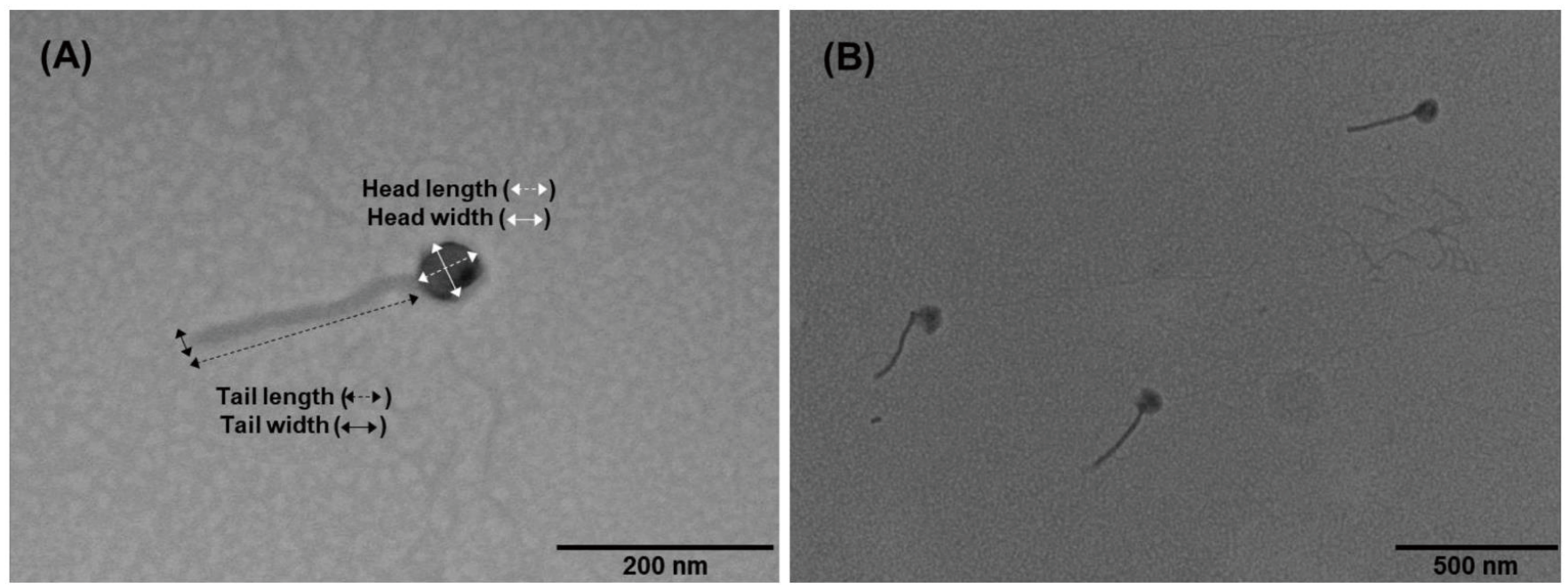

Fig. 1. Transmission electron microscopy image of Salmonella Typhimurium-specific phage (KFS-ST) with magnification of $(A) \times 50.0 \mathrm{k}$ and $(\mathrm{B}) \times 15.0 \mathrm{k}$. 


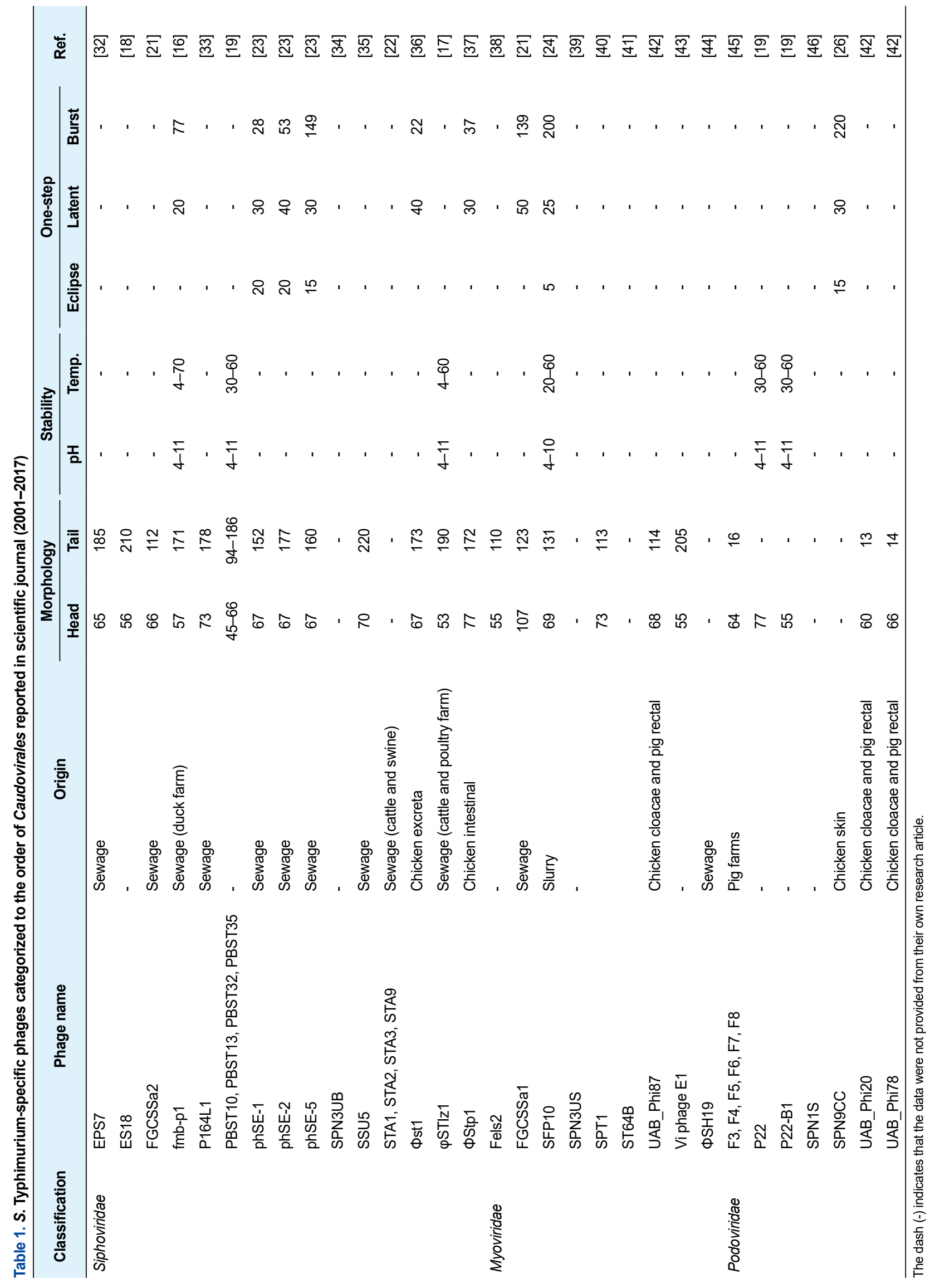


identify the target pathogen among others in a sample and is a very important factor for consideration [9]. Although KFS-ST was purified with great concentration, the specificity needs to be guaranteed for its further use. KFS-ST exhibited clear zones against only $S$. Typhimurium and $S$. Enteritidis among the 12 tested Salmonella strains. More interestingly, no clear zones were identified against $S$. Heidelberg, $S$. Hartford, $S$. Mission, $S$. Montevideo, S. Salamae, and S. Senftenberg, which are considered the most problematic Salmonella stains reported from the CDC [3]. More importantly, KFS-ST did not exhibit any cross-genus specificity against 27 other non-Salmonella pathogens. Therefore, it was concluded that KFS-ST had great specificity against three strains of $S$. Typhimurium and $S$. Enteritidis with an EOP of approximately 1 (Table 2).

The specificity of phages is associated with the their capacity to bind to host receptors such as

Table 2. Specificity Salmonella Typhimurium-specific phage (KFS-ST) isolated from poultry industry

\begin{tabular}{|c|c|c|c|}
\hline Bacterial strain & Clear zone formation ${ }^{1)}$ & $\mathrm{EOP}^{2)}$ & Source \\
\hline \multicolumn{4}{|l|}{ Salmonella spp. } \\
\hline S. Typhimurium ATCC 13311 & + & $1.00 \pm 0.00$ & ATCC \\
\hline S. Typhimurium ATCC 14028 & + & $1.00 \pm 0.02$ & ATCC \\
\hline S. Typhimurium NCCP 10812 & + & $0.98 \pm 0.01$ & ATCC \\
\hline S. Enteritidis ATCC 13076 & + & $1.00 \pm 0.01$ & ATCC \\
\hline S. Enteritidis NCCP 12243 & + & $0.99 \pm 0.01$ & NCCP \\
\hline S. Enteritidis NCCP 14771 & + & $1.00 \pm 0.02$ & NCCP \\
\hline S. Heidelberg & - & - & DPFS \\
\hline S. Hartford & - & - & DPFS \\
\hline S. Mission & - & - & DPFS \\
\hline S. Montevideo & - & - & DPFS \\
\hline S. Salamae & - & - & DPFS \\
\hline S. Senftenberg & - & - & DPFS \\
\hline \multicolumn{4}{|l|}{ Non-Salmonella strains } \\
\hline Aeromonas hydrophila ATCC 7966 & - & - & ATCC \\
\hline Bacillus cereus ATCC 13061 & - & - & ATCC \\
\hline B. cereus ATCC 1611 & - & - & ATCC \\
\hline B. cereus ATCC 21768 & - & - & ATCC \\
\hline B. cereus ATCC 14579 & - & - & ATCC \\
\hline Escherichia coli O157:H7 ATCC 43895 & - & - & ATCC \\
\hline E. coli O157:H7 ATCC 700599 & - & - & ATCC \\
\hline E. coli O157:H7 rif R & - & - & DPFS \\
\hline E. coli O157:H7 204p & - & - & DPFS \\
\hline E. coli ATCC BAA-2192 & - & - & ATCC \\
\hline E. coli ATCC BAA-2196 & - & - & ATCC \\
\hline E. coli BW 25113 & - & - & DPFS \\
\hline E. coli ER 2738 & - & - & DPFS \\
\hline E. coli K12 VSM 1692 & - & - & DPFS \\
\hline Klebsiella pneumoniae ATCC 13883 & - & - & ATCC \\
\hline Listeria innocua ATCC 33090 & - & - & ATCC \\
\hline L. monocytogenes ATCC 19111 & - & - & ATCC \\
\hline L. monocytogenes G3982 4b & - & - & DPFS \\
\hline L. monocytogenes G6055 & - & - & DPFS \\
\hline L. monocytogenes $\mathrm{H} 7738$ & - & - & DPFS \\
\hline L. monocytogenes $\mathrm{H} 7757$ & - & - & DPFS \\
\hline Pseudomonas aeruginosa ATCC 9027 & - & - & ATCC \\
\hline Shigella boydii NCCP 11190 & - & - & NCCP \\
\hline S. flexneri $2457 \mathrm{~T}$ & - & - & DPFS \\
\hline S. sonnei ATCC 9290 & - & - & ATCC \\
\hline Staphylococcus aureus ATCC 25923 & - & - & ATCC \\
\hline Vibrio parahaemolyticus ATCC 17802 & - & - & ATCC \\
\hline
\end{tabular}

${ }^{1)}+$, clear zone formation; - , no plaque.

${ }^{2}$ The EOP values were shown as mean \pm SD from three independent experiments. 
flagella, capsules, lipopolysaccharides and proteins in the outer membrane or slime layer [19]. Although several studies have confirmed the specificity of phage, there is no clear definition of the narrow- and broad-specificity of phages [20]. Carey-Smith et al. [21] reported that FGCSSa2 ( $S$. Typhimurium-specific phage) showed species-level specificity due to its lytic activity against only three strains of $S$. Typhimurium among eight other strains of Salmonella including $S$. Typhimurium, $S$. Infentis, $S$. Menston $S$. Saintpaul, $S$. Entertidis and two Escherichia coli strains. Akhtar et al. [22] demonstrated that STA3, STA9 and STA10 ( $S$. Typhimurium-specific phages) had species-level specificities against only $S$. Typhimurium and $S$. Heidelberg among 27 strains of Salmonella, which was very similar to the results of our study. In addition, Wang et al.'s study [16] exhibited more broad species-level specificity by demonstrating that fmb-p1 ( $S$. Typhimurium-specific phage) was specific to 10 of 34 Salmonella strains including $S$. Typhimurium, $S$. Enteritidis, S. Agona, S. Anatum, $S$. Heidelberg, $S$. Miami, $S$. Paratyphi-C, and $S$. Thompson without any specificities against non-Salmonella strains including Listeria monocytogenes, E. coli, Staphylococcus aureus and Bacillus subtilis. Meanwhile, Pereira et al. [23] reported that phSE-1 and phSE-2 (S. Typhimurium-specific phages) showed genus-level specificity against 27 strains of 42 foodborne pathogens, including three strains of $S$. Typhimurium strains, five strains of $S$. Enteritidis strains, eleven strains of $E$. coli strains, two strains of Citrobacter freundii strains, four species of Providencia, Klebsiella pneumonia, and Enterobacter cloacae. In addition, phSE-3 ( $S$. Typhimurium-specific phages) showed genus-level specificity against 25 of 42 strains including three strains of $S$. Typhimurium, five strains of $S$. Enteritidis, ten strains of $E$. coli, two strains of Citrobacter freundii, and four species of Providencia sp. and Klebsiella pneumonia. Furthermore, Park et al. [24] reported the genus-level specificity of SFP10 ( $S$. Typhimurium-specific phages) infecting seven strains of $S$. Typhimurium and $S$. Enteritidis, two strains of $S$. Paratyphi and $S$. Dublin and four strains of $E$. coli. Overall, KFS-ST exhibited great narrow specificity against only $S$. Typhimurium and Enteritidis, which are considered major Salmonella strains in meat and poultry [7]. This excellent specificity will satisfy one of requirements for selecting a bio-receptor for use in the ME biosensor method.

\section{Temperature and pH stabilities of KFS-ST}

A phage-based ME biosensor may be exposed to various environmental conditions for the detection of $S$. Typhimurium and $S$. Enteritidis on poultry products that undergo various harsh conditions during processing and storage. Since major components of phage are nucleic acid and structural proteins, the structural proteins and DNA of phage could be damaged under harsh external conditions, such as extreme temperature and $\mathrm{pH}$ [25]. As shown in Fig. 2A, KFS-ST sustained its concentration at a temperature range between $4^{\circ} \mathrm{C}$ and $50^{\circ} \mathrm{C}$. After that, the concentration of KFSST significantly decreased at $-20^{\circ} \mathrm{C}\left(17.7 \%\right.$ reduction), $-70^{\circ} \mathrm{C}\left(43.5 \%\right.$ reduction), and $60^{\circ} \mathrm{C}(30.5 \%$ reduction) $(p<0.05)$. Jonczyk et al. [25] reported that the phages that belonged to the Siphoviridae family were the most resistant to adverse conditions. In terms of temperature stability, $\varphi S T I z 1(S$. Typhimurium-specific phages) [17] exhibited relatively similar temperature stability $\left(4^{\circ} \mathrm{C}-60^{\circ} \mathrm{C}\right)$ with our results. Meanwhile, PBST10, PBST13, PBST32 as $S$. Typhimurium-specific phages [19] exhibited very narrow temperature ranges of $30^{\circ} \mathrm{C}-60^{\circ} \mathrm{C}$. Interestingly, fmb-p1 [16] also represented a further narrow temperature stability of $40^{\circ} \mathrm{C}-75^{\circ} \mathrm{C}$.

In regards to $\mathrm{pH}$, the stability of phage confirmed by the concentration of KFS-ST phage was sustained at the $\mathrm{pH}$ range of 4 to 12 (Fig. 2B). Only approximately $8.1 \%$ reduction of phage concentration was observed in this range, although the KFS-ST concentration was significantly decreased at $\mathrm{pH} 4$ and $\mathrm{pH} 12(p<0.05)$. However, the phage concentration was reduced continuously up to $29.5 \%$ at a $\mathrm{pH} 3$ and finally lost the concentration completely at $\mathrm{pH} 1$ and $\mathrm{pH} 2$ ( $99.9 \%$ reduction) $(p<0.05)$. Based on previous studies, $\varphi$ STIz1 [17], PBST10 [19], PBST13 
(A)

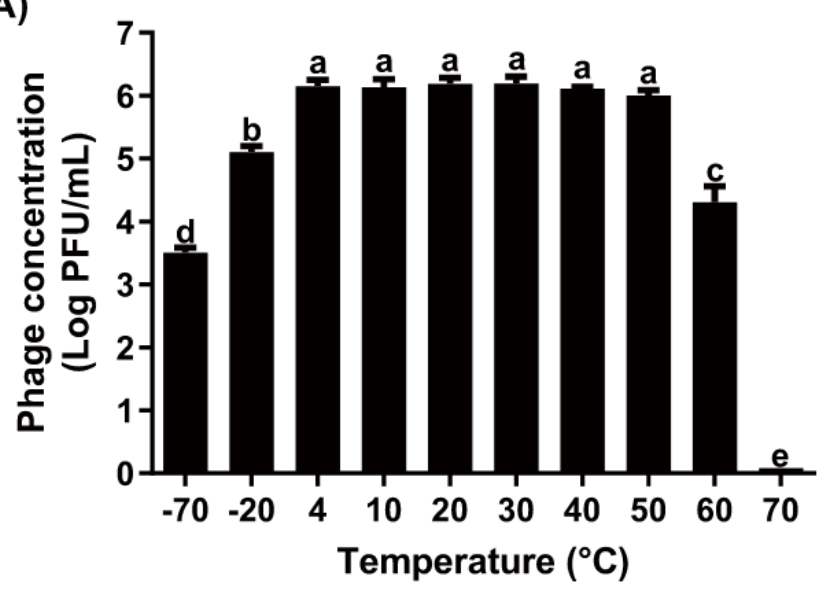

(B)

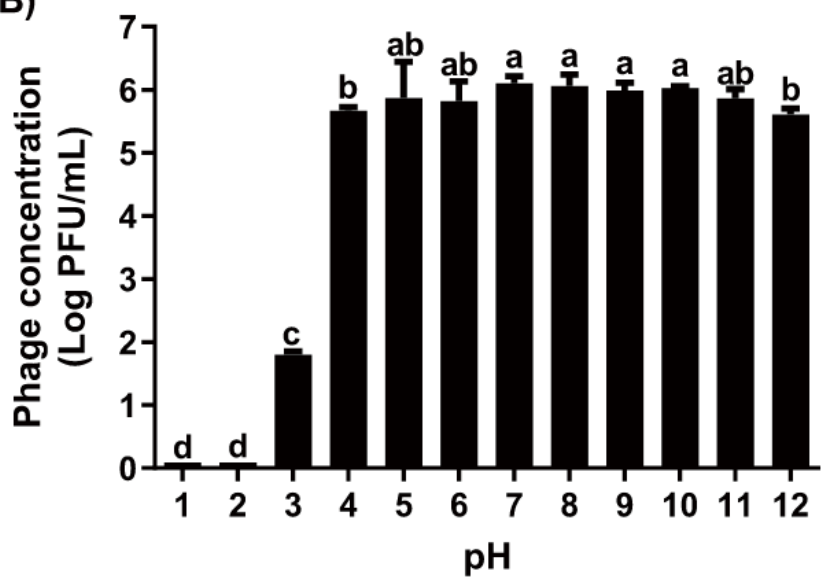

Fig. 2. Stability of Salmonella Typhimurium-specific phage (KFS-ST) at various (A) temperatures and (B) pHs. ${ }^{a-e}$ Different letters within treatment indicate significant differences.

[19], PBST32 [19], PBST35 [19] and fmb-p1 [16] showed similar pH stability with our studies. Although no clear standards for stability has been established for the optimum phage, our results highlight the relatively broad temperature stability and competitive $\mathrm{pH}$ stability of KFS-ST for practical use under various environmental conditions.

\section{One-step growth curve of KFS-ST}

Most phages (approximately 90\%) that are isolated from the environment are lytic and tailed phages [9]. Although a lytic property is necessary for identifying and purifying of phages from the environment, it is not always beneficial for use as a bio-receptor. Specifically, the ME biosensor is dependent on a mass change on the sensor so that the immobilized phages on the sensor must be sustained without any rupture of bacteria due to its lytic activity. Thus, the eclipse time, latent time and burst size of KFS-ST phage were determined using a one-step growth curve analysis (Fig. 3). The eclipse time of phage indicates the time interval between infection and replication of the phage inside the host cell; it was $10 \mathrm{~min}$ for KFS-ST after 25-min adsorption time. The latent time, which

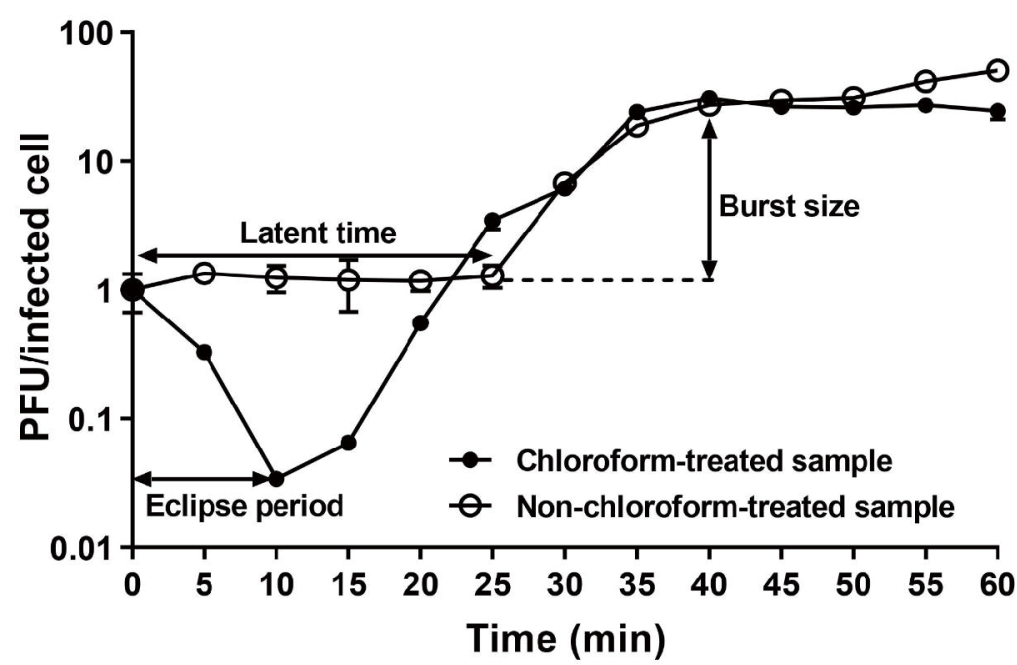

Fig. 3. One step growth curve of Salmonella Typhimurium-specific phage (KFS-ST). 
is the time interval between the infection and the release of the first phage from the host, was 25 min after adsorption. The burst size of KFS-ST from a single infected bacterial cell was determined as $26 \mathrm{PFU} /$ one infected cell.

Once phage adsorbed, the latent time and eclipse time were compared with those of other studies. The eclipse time of KFS-ST was longer than that of SFP10 phage, which had an eclipse time of 5 min [24]. On the contrary, our eclipse time was shorter than that of other $S$. Typhimurium-specific phages including SPN9CC (15 min) [26], phSE-1 (20 min), phSE-2 (20 min), and phSE5 (15 $\mathrm{min}$ ) [23]. When employing KFS-ST as a bio-receptor on ME biosensor, the best desirable detection time is within the adsorption time. Just in case the lytic phage goes into the bacterial cell, the overall detection time of the ME biosensor needs to be complete before the combined time of the adsorption time and eclipse time. Our previous studies have confirmed that the total detection time of the ME biosensor including the placement and incubation of phage-immobilized sensor on the surface of the food along with detection by a network analyzer, was 15 min, provided the phage was previously immobilized on the ME sensor. Therefore, the adsorption and eclipse time of KFSST provides sufficient time for the phages to bind with Salmonella on the surface of contaminated poultry and meat for its quantification and qualification without any mass loss.

\section{Storage stability of KFS-ST}

Antibodies are the most popularly employed bio-receptor, however, their most considerable limitations include their need for storage at cold temperatures and their average shelf life of one month [27]. By contrast phage possess excellent stability at relatively broad temperature ranges during long periods [28]. Thus, the influence of storage period and temperature were investigated by measuring the concentration of KFS-ST after exposure to various storage conditions over a period of 12 weeks (Table 3). As long as their storage period increased, their concentration decreased with a similar stability pattern among various temperatures. Although phage concentration decreased significantly, their final decreases during the 12 weeks were only $0.31 \log , \sim 0.28 \log , \sim 0.25 \log$ and $\sim 0.25 \log$ at temperatures of $-70^{\circ} \mathrm{C},-20^{\circ} \mathrm{C}, 4^{\circ} \mathrm{C}$, and $22^{\circ} \mathrm{C}$, respectively $(p<0.05)$. When compared with various temperatures over the same storage period, there were no significant differences among them, except for $-70^{\circ} \mathrm{C}$ at 12 weeks $(p<0.05)$. Therefore, our phage exhibited a robust and broad storage stability including deep freezing, freezing, cold and room temperatures, suggesting that it has a very competitive factor for use as a novel bio-receptor.

Petsong et al. [29] reported that the concentration of Salmonella-specific phage cocktail including SLP004, SLP005 and SLP050 was reduced by $~ 1 \log$ after 5 weeks and $\sim 4 \log$ after 12 weeks at $4^{\circ} \mathrm{C}$. In the meantime, the phage cocktail lost its concentration completely after 4 weeks at $25^{\circ} \mathrm{C}$. The room temperature accelerated the reduction of the phage cocktail concentration more than

Table 3. Stability of Salmonella Typhimurium-specific phage (KFS-ST) stored at various temperatures

\begin{tabular}{ccccc}
\hline \multirow{2}{*}{ Periods (wk) } & \multicolumn{4}{c}{ Temperature $\left({ }^{\circ} \mathrm{C}\right)$} \\
\cline { 2 - 5 } & $\mathbf{- 7 0}$ & $\mathbf{- 2 0}$ & $\mathbf{4}$ & $\mathbf{2 2}$ \\
\hline 0 & $9.20 \pm 0.02^{\mathrm{ax}}$ & $9.20 \pm 0.02^{\mathrm{ax}}$ & $9.20 \pm 0.02^{\mathrm{ax}}$ & $9.20 \pm 0.02^{\mathrm{ax}}$ \\
2 & $9.15 \pm 0.04^{\mathrm{bx}}$ & $9.08 \pm 0.05^{\mathrm{bx}}$ & $9.15 \pm 0.06^{\mathrm{abx}}$ & $9.11 \pm 0.00^{\mathrm{bx}}$ \\
4 & $9.07 \pm 0.02^{\mathrm{bx}}$ & $9.08 \pm 0.05^{\mathrm{bx}}$ & $9.15 \pm 0.03^{\mathrm{abx}}$ & $9.11 \pm 0.01^{\mathrm{bx}}$ \\
6 & $8.99 \pm 0.08^{\mathrm{bx}}$ & $9.03 \pm 0.01^{\mathrm{cdx}}$ & $9.09 \pm 0.04^{\mathrm{bcx}}$ & $9.10 \pm 0.03^{\mathrm{bx}}$ \\
8 & $9.01 \pm 0.02^{\mathrm{bx}}$ & $9.02 \pm 0.02^{\mathrm{dx}}$ & $9.05 \pm 0.02^{\mathrm{cx}}$ & $9.05 \pm 0.03^{\mathrm{cx}}$ \\
10 & $8.99 \pm 0.01^{\mathrm{bx}}$ & $9.00 \pm 0.02^{\mathrm{dx}}$ & $9.00 \pm 0.02^{\mathrm{cdx}}$ & $9.02 \pm 0.02^{\mathrm{cx}}$ \\
12 & $8.89 \pm 0.01^{\mathrm{cy}}$ & $8.92 \pm 0.02^{\mathrm{exy}}$ & $8.95 \pm 0.01^{\mathrm{dx}}$ & $8.95 \pm 0.00^{\mathrm{dx}}$ \\
\hline
\end{tabular}

${ }^{a-d, x-y}$ Means with different letters are significantly different within column and row, respectively $(p<0.05, n=3)$. 
cold temperature in this study. The other study [28] also confirmed the lower feasibility of Yersinia enterocolitica-specific phage when exposed to room temperature rather than deep freezing, freezing, and cold temperatures. In fact, most of the several commercial phage cocktails approved by the FDA were sold under cold storage conditions $\left(2^{\circ} \mathrm{C}-8^{\circ} \mathrm{C}\right)$ [30]. Even another study [31] has confirmed that the best condition for phage storage is a cold temperature range in most cases. The fact that the stability of KFS-ST at room temperature was maintained at a similar level with cold and freezing temperatures during the whole storage period provides a considerable advantage for the process of carrying and storing KFS-ST for its practical aspect as a novel bio-receptor.

\section{CONCLUSION}

This study highlights the feasibility of KFS-ST isolated from a poultry processing facility to search for host-specific phage as a novel bio-receptor that will be used in the ME biosensor method for the detection of $S$. Typhimurium and $S$. Enteritidis in poultry products. The phage exhibited morphological characteristics, such as a relatively longer non-contractile tail with an icosahedral head, and was highly specific to $S$. Typhimurium and $S$. Enteritidis only. Along with excellent specificity, the phage exhibited relatively broad temperature and competitive $\mathrm{pH}$ stabilities. Furthermore, a one-step growth analysis of KFS-ST guaranteed that it provided enough time to bind with Salmonella without any phage-related ruptures for its quantification. Additionally, it possessed excellent storage stability even at room temperature, which was a highly competitive factor for commercial use. In fact, a few studies have employed Salmonella-specific phages on the ME biosensor method for the detection of Salmonella on meat and poultry products. These phages, including E2 phage $[12,13]$ and C4-22 phage [14], were obtained from genetic modification technology for improving their original binding affinity and specificity. Although all of these phages were able to detect Salmonella successfully, the phage typing technology required time- and labor-consuming procedures. Furthermore, their filamentous morphologies induced the aggregation problem when employed to the ME biosensor method. In order to overcome these limitations of previously employed phages, a highly specific tailed-type KFS-ST phage was isolated and purified by using the specific interaction between the phage with a target pathogen existing in poultry. The practical feasibility of this phage was then confirmed in this study. Finally, this study will open the door for further practical developments of tailed-type KFS-ST as a novel bio-receptor by employing it to ME biosensor method for detection of Salmonella on meat and poultry product.

\section{REFERENCES}

1. CDC [Centers for Disease Control and Prevention]. Salmonella [Internet]. 2020. [cited 2020 Jul 14]. https://www.cdc.gov/salmonella/

2. Kurtz JR, Goggins JA, McLachlan JB. Salmonella infection: interplay between the bacteria and host immune system. Immunol Lett. 2017;190:42-50. https://doi.org/10.1016/j.imlet.2017.07.006

3. Oh JH, Park MK. Recent trends in Salmonella outbreaks and emerging technology for biocontrol of Salmonella using phages in foods: a review. J Microbiol Biotechnol. 2017;27:207588. https://doi.org/10.4014/jmb.1710.10049

4. Blaser MJ, Newman LS. A review of human salmonellosis: I. infective dose. Rev Infect Dis. 1982;4:1096-106. https://doi.org/10.1093/clinids/4.6.1096

5. Kim HB, Yoon M, Lee S, Jang Y, Choe N. Prevalence and antibiotic resistance characteristics of Salmonella spp. isolated from food-producing animals and meat products in Korea. J Prev 
Vet Med. 2014;38:85-93. https://doi.org/10.13041/jpvm.2014.38.4.85

6. Antunes P, Mourão J, Campos J, Peixe L. Salmonellosis: the role of poultry meat. Clin Microbiol Infect. 2016;22:110-21. https://doi.org/10.1016/j.cmi.2015.12.004

7. Kim S, Kim SH, Chun SG, Choi ES, Lee BK, Group SS. Prevalence of Salmonella serovars isolated from domestic residents and overseas travelers in Korea, 2004-2005. J Bacteriol Virol. 2006;36:69-72. https://doi.org/10.4167/jbv.2006.36.2.69

8. Ricci F, Volpe G, Micheli L, Palleschi G. A review on novel developments and applications of immunosensors in food analysis. Anal Chim Acta. 2007;605:111-29. https://doi.org/10.1016/ j.aca.2007.10.046

9. Choi IY, Lee C, Song WK, Jang SJ, Park MK. Lytic KFS-SE2 phage as a novel bio-receptor for Salmonella Enteritidis detection. J Microbiol. 2019;57:170-9. https://doi.org/10.1007/ s12275-019-8610-0

10. Park MK, Weerakoon KA, Oh JH, Chin BA. The analytical comparison of phage-based magnetoelastic biosensor with TaqMan-based quantitative PCR method to detect Salmonella Typhimurium on cantaloupes. Food Control. 2013;33:330-6. https://doi.org/10.1016/j.foodcont.2013.02.026

11. Park MK, Hirematha N, Weerakoon K, Vaglenov KA, Barbaree JM, Chin BA. Effects of surface morphologies of fresh produce on the performance of phage-based magnetoelastic biosensors. J Electrochem Soc. 2012;160:B6-12. https://doi.org/10.1149/2.059301jes

12. Lakshmanan RS, Guntupalli R, Hu J, Petrenko VA, Barbaree JM, Chin BA. Detection of Salmonella typhimurium in fat free milk using a phage immobilized magnetoelastic sensor. Sens Actuators B Chem. 2007;126:544-50. https://doi.org/10.1016/j.snb.2007.04.003

13. Chai Y, Li S, Horikawa S, Park MK, Vodyanoy V, Chin BA. Rapid and sensitive detection of Salmonella Typhimurium on eggshells by using wireless biosensors. J Food Prot. 2012;75:6316. https://doi.org/10.4315/0362-028X.JFP-11-339

14. Chen IH, Horikawa S, Bryant K, Riggs R, Chin BA, Barbaree JM. Bacterial assessment of phage magnetoelastic sensors for Salmonella enterica Typhimurium detection in chicken meat. Food Control.2017;71:273-8. https://doi.org/10.1016/j.foodcont.2016.07.003

15. Ackermann HW, DuBow M, Jarvis AW, Jones LA, Krylov VN, Maniloff J, et al. The species concept and its application to tailed phages. Arch Virol. 1992;124:69-82. https://doi. org/10.1007/BF01314626

16. Wang C, Chen Q, Zhang C, Yang J, Lu Z, Lu F, et al. Characterization of a broad host-spectrum virulent Salmonella bacteriophage fmb-p1 and its application on duck meat. Virus Res. 2017;236:14-23. https://doi.org/10.1016/j.virusres.2017.05.001

17. Kerketta P, Agarwal RK, Rawat M, Jain L, Kumar PP, Dhanze H, et al. Isolation and characterization of lytic bacteriophage ( $\phi$ STIz1) against Salmonella enterica serovars Typhimurium. J Pure Appl Microbiol. 2014;8:4719-26.

18. Casjens SR, Gilcrease EB, Winn-Stapley DA, Schicklmaier P, Schmieger H, Pedulla ML, et al. The generalized transducing Salmonella bacteriophage ES18: complete genome sequence and DNA packaging strategy. J Bacteriol. 2005;187:1091-104. https://doi.org/10.1128/ JB.187.3.1091-1104.2005

19. Jung LS, Ding T, Ahn J. Evaluation of lytic bacteriophages for control of multidrug-resistant Salmonella Typhimurium. Ann Clin Microbiol Antimicrob. 2017;16:66. https://doi. org/10.1186/s12941-017-0237-6

20. Ross A, Ward S, Hyman P. More is better: selecting for broad host range bacteriophages. Front Microbiol. 2016;7:1352. https://doi.org/10.3389/fmicb.2016.01352

21. Carey-Smith GV, Billington C, Cornelius AJ, Hudson JA, Heinemann JA. Isolation and char- 
acterization of bacteriophages infecting Salmonella spp. FEMS Microbiol Lett. 2006;258:1826. https://doi.org/10.1111/j.1574-6968.2006.00217.x

22. Akhtar M, Viazis S, Diez-Gonzalez F. Isolation, identification and characterization of lytic, wide host range bacteriophages from waste effluents against Salmonella enterica serovars. Food Control. 2014;38:67-74. https://doi.org/10.1016/j.foodcont.2013.09.064

23. Pereira C, Moreirinha C, Lewicka M, Almeida P, Clemente C, Cunha Â, et al. Bacteriophages with potential to inactivate Salmonella Typhimurium: use of single phage suspensions and phage cocktails. Virus Res. 2016;220:179-92. https://doi.org/10.1016/j.virusres.2016.04.020

24. Park M, Lee JH, Shin H, Kim M, Choi J, Kang DH, et al. Characterization and comparative genomic analysis of a novel bacteriophage, SFP10, simultaneously inhibiting both Salmonella enterica and Escherichia coli O157: H7. Appl Environ Microbiol. 2012;78:58-69. https://doi. org/10.1128/AEM.06231-11

25. Jończyk E, Kłak M, Międzybrodzki R, Górski A. The influence of external factors on bacteriophages. Folia Microbiol. 2011;56:191-200. https://doi.org/10.1007/s12223-011-0039-8

26. Shin H, Lee JH, Yoon H, Kang DH, Ryu S. Genomic investigation of lysogen formation and host lysis systems of the Salmonella temperate bacteriophage SPN9CC. Appl Environ Microbiol. 2014;80:374-84. https://doi.org/10.1128/AEM.02279-13

27. Peltomaa R, Benito-Peña E, Barderas R, Moreno-Bondi MC. Phage display in the quest for new selective recognition elements for biosensors. ACS Omega. 2019;4:11569-80. https://doi. org/10.1021/acsomega.9b01206

28. Gwak KM, Choi IY, Lee J, Oh J, Park M. Isolation and characterization of a lytic and highly specific phage against Yersinia enterocolitica as a novel biocontrol agent. J Microbiol Biotechnol. 2018;28:1946-54. https://doi.org/10.4014/jmb.1808.08001

29. Petsong K, Benjakul S, Vongkamjan K. Evaluation of storage conditions and efficiency of a novel microencapsulated Salmonella phage cocktail for controlling S. enteritidis and S. typhimurium in-vitro and in fresh foods. Food Microbiol. 2019;83:167-74. https://doi.org/10.1016/ j.fm.2019.05.008

30. Chang RYK, Wallin M, Lin Y, Leung SSY, Wang H, Morales S, et al. Phage therapy for respiratory infections. Adv Drug Delivery Rev. 2018;133:76-86. https://doi.org/10.1016/j.addr.2018.08.001

31. Weber-Dąbrowska B, Jończyk-Matysiak E, Żaczek M, Łobocka M, Łusiak-Szelachowska M, Górski A. Bacteriophage procurement for therapeutic purposes. Front Microbiol. 2016;7:1177. https://doi.org/10.3389/fmicb.2016.01177

32. Hong J, Kim KP, Heu S, Lee SJ, Adhya S, Ryu S. Identification of host receptor and receptor-binding module of a newly sequenced T5-like phage EPS7. FEMS Microbiol Lett. 2008;289:202-9. https://doi.org/10.1111/j.1574-6968.2008.01397.x

33. Gunathilaka GU. Characterization of bacteriophages from environmental water samples and the potential of bacteriophages tailspike proteins (tsp) in bacteria detection [Master's thesis]. Detroit, MI: Wayne State University; 2014.

34. Lee JH, Shin H, Ryu S. Complete genome sequence of Salmonella enterica serovar Typhimurium bacteriophage SPN3UB.J Virol. 2012;86:3404-5. https://doi.org/10.1128/JVI.07226-11

35. Kim S. Isolation and characterization of bacteriophage SSU5 specific for Salmonella enterica serovar Typhimurium rough strain [Master's thesis]. Seoul: Seoul National University; 2013.

36. Wong CL, Sieo CC, Tan WS, Abdullah N, Hair-Bejo M, Abu J, et al. Evaluation of a lytic bacteriophage, $\Phi$ st1, for biocontrol of Salmonella enterica serovar Typhimurium in chickens. Int J Food Microbiol. 2014;172:92-101. https://doi.org/10.1016/j.ijfoodmicro.2013.11.034

37. Sritha K, Bhat SG. Genomics of Salmonella phage $\Phi$ Stp1: candidate bacteriophage for bio- 
control. Virus Genes. 2018;54:311-8. https://doi.org/10.1007/s11262-018-1538-3

38. Bunny K, Liu J, Roth J. Phenotypes of lexA mutations in Salmonella enterica: evidence for a lethal lexA null phenotype due to the Fels-2 prophage.J Bacteriol. 2002;184:6235-49. https:// doi.org/10.1128/JB.184.22.6235-6249.2002

39. Lee JH, Shin H, Kim H, Ryu S. Complete genome sequence of Salmonella bacteriophage SPN3US.J Virol. 2011; 85:13470-1. https://doi.org/10.1128/JVI.06344-11

40. Voelker R, Sulakvelidze A, Ackermann HW. Spontaneous tail length variation in a Salmonella myovirus. Virus Res. 2005;114:164-6. https://doi.org/10.1016/j.virusres.2005.05.006

41. Mmolawa PT, Schmieger H, Heuzenroeder MW. Bacteriophage ST64B, a genetic mosaic of genes from diverse sources isolated from Salmonella enterica serovar Typhimurium DT 64. J Bacteriol.2003;185:6481-5. https://doi.org/10.1128/JB.185.21.6481-6485.2003

42. Bardina C, Spricigo DA, Cortés P, Llagostera M. Significance of the bacteriophage treatment schedule in reducing Salmonella colonization of poultry. Appl Environ Microbiol. 2012;78:6600-7. https://doi.org/10.1128/AEM.01257-12

43. Pickard D, Thomson NR, Baker S, Wain J, Pardo M, Goulding D, et al. Molecular characterization of the Salmonella enterica serovar Typhi Vi-typing bacteriophage E1. J Bacteriol. 2008;190:2580-7. https://doi.org/10.1128/JB.01654-07

44. Hooton SPT, Timms AR, Rowsell J, Wilson R, Connerton IF. Salmonella typhimurium-specific bacteriophage $\Phi \mathrm{SH} 19$ and the origins of species specificity in the Vi01-like phage family. Virol J.2011;8:498. https://doi.org/10.1186/1743-422X-8-498

45. Albino LA, Rostagno MH, Húngaro HM, Mendonça RC. Isolation, characterization, and application of bacteriophages for Salmonella spp. biocontrol in pigs. Foodborne Pathog Dis. 2014;11:602-9. https://doi.org/10.1089/fpd.2013.1600

46. Shin H, Lee JH, Lim JA, Kim H, Ryu S. Complete genome sequence of Salmonella enterica serovar Typhimurium bacteriophage SPN1S. J Virol. 2012;86:1284-5. https://doi.org/10.1128/ JVI.06696-11 